\title{
SAÚDE EM CUBA: DISCURSO DE ÓDIO E RETOMADAS DE DISCURSOS CONSERVADORES ${ }^{i}$
}

\section{Gabriel Reis Moraes Machiavelii}

Resumo: O artigo tem o propósito de identificar e investigar os discursos de ódio no Facebook através dos comentários de usuários na rede. Discurso de ódio entendido como conjunto de enunciados regulares e parcialmente estáveis que busca ferir o outro seja por sua etnia, orientação sexual, situação econômica, entre outros predicados com viés de humilhação e/ou hostilização. A análise será feita a partir das contribuições de Guilbert (2007) e Zizek (1996a; 1996b) sobre a materialização da ideologia em comentários no Facebook. O trabalho sugere que os enunciados são reflexões de condições sócio-históricas anteriores, como, por exemplo, a Guerra Fria, no pós-guerra, e a implantação da Ditadura Militar, no Brasil, em 1964.

Palavras-chave: Discurso. Facebook. Ideologia. Ódio

Abstract: The article aims to identify and investigate hate speeches on Facebook instantiated in the comments of users on the network. Hate speeches are understood as a set of regular and partially stable utterances that seek to hurt the other, because of their ethnicity, sexual orientation, economic status, among other predicates with humiliation and/or harassment bias. The analysis will draw upon the contributions of Guilbert (2007) and Zizek (1996a; 1996b) on the materialization of ideology in Facebook comments. The work suggests that the statements are reflections of previous socio-historical conditions, such as the Cold War, the post-war, and the military dictatorship that began in 1964 in Brazil.

Keywords: Discourse. Facebook. Ideology. Hate.

\footnotetext{
Trabalho apresentado inicialmente no IX Congresso Internacional de la Associacíon Latinoamericana de Estudos del Discurso (ALED), de forma resumida, em novembro de 2015.

ii Mestre em Teoria Literária e Crítica da Cultura pela Universidade Federal de São João Del-Rei (UFSJ). E-mail: gabriel.machiaveli@gmail.com.
} 
EID\&A - Revista Eletrônica de Estudos Integrados em Discurso e Argumentação, Ilhéus, n. 12, jul/dez.2016.

\section{Introdução}

Há muitas discussões atualmente em torno da existência de uma polarização entre direita e esquerda politicamente. Isto porque parte das iniciativas partidárias estão, cada vez mais, se confluindo numa bandeja que carrega o poder e lutam por ele a qualquer custo. A existência ou não de uma filiação à/de direita ou à/de esquerda não esgota todos os reflexos históricos que estas correntes proporcionaram na sociedade. Como, por exemplo, a instalação da União Soviética e a polarização que a Guerra Fria gerou mundialmente. Estes reflexos são representados de diversas formas, mas o que desponta, geralmente, é o caráter ideológico que vários enunciados proclamam em polarizar as duas linhas de pensamento. Se temos este caráter ideológico, temos uma fonte de sustentação: o discurso. Com isso, o objetivo geral deste trabalho é identificar e investigar como ocorrem as materializações ideológicas nos dizeres, especialmente, em comentários de usuários na rede social Facebook.

Para isso, tomamos como corpus uma gama de comentários e réplicas publicados em três páginas de jornais tradicionais imersos na rede social Facebook. São eles: O Estado de São Paulo, O Globo, e Folha de São Paulo. Com o tema de que Cuba fora o primeiro país a eliminar a transmissão de HIV de mãe para filho, publicado em 30 de junho de 2015, conseguimos coletar o primeiro comentário de 3 postagens dos jornais supracitados, contendo 186 respostas ou réplicas. Nosso objetivo é analisar a materialização ideológica dos comentários e réplicas utilizando a teoria de Guilbert (2007) como operacionalização analítica.

Desde o início do governo do Partido dos Trabalhadores (PT), iniciam-se debates em torno da esquerda estar no poder e querer implantar o socialismo no Brasil. Entretanto, por mais que o partido se dirija à ala da esquerda, suas políticas econômicas demonstram que, na verdade, há uma centro-esquerda, ou uma política neo-desenvolvimentista, ao invés do socialismo de Cuba, ou do neo-socialismo de Hugo Chávez na Venezuela. Portanto, politicamente, é difícil dizer se realmente existem as correntes de esquerda e direita, mas reflexos delas alavancados pelo acesso de pessoas a redes sociais, como o Facebook, mostram como os embates ocorridos há anos ainda se materializam em forma de deslegitimar a ação do outro, e de reforçar ideias contrastantes.

Com o impeachment da presidenta Dilma Rousseff (PT) em 2016, acusada e condenada pelas "pedaladas fiscais", apelido dado pela mídia 
EID\&A - Revista Eletrônica de Estudos Integrados em Discurso e Argumentação, Ilhéus, n. 12, jul/dez.2016.

brasileira a empréstimos de dinheiros de bancos públicos para o pagamento de benefícios sociais e pelos decretos de créditos especiais publicados em 2015, O presente trabalho se justifica para compreender as relações ideológicas que os sujeitos arregimentam em sites de redes sociais, em especial, o Facebook. Com a ascensão, ou melhor, o desadormecimento de uma classe conservadora, este trabalho pretende compreender, também, a relação dialógica e dialética das polarizações instaladas no país. Com fortes manifestações contra o presidente Michel Temer (PMDB), a presente análise se justifica para compreender estas relações e talvez apontar resquícios da retomada de discursos em épocas passadas, como a Ditadura Civil-Militar no Brasil (1964-1985) e a Guerra Fria (1945-1991).

\section{Ideologia como fantasia e sacralização}

A força da evidência e a evidência eterna pode ser entendida, citando Althusser (1998), como um dos conceitos de ideologia. Um processo do qual, o sujeito, inserido em uma determinada condição social, é interpelado por uma força, a qual o convoca a atuar como sujeito. Já dizia Althusser (1998): só há ideologia para e por sujeitos. Portanto, em Aparelhos Ideológicos do Estado (AIE), o autor aponta como a ideologia se materializa num processo imaginário da realidade a partir das instituições de repressão do Estado (como a polícia, penitenciárias, entre outras) e ideológicas do Estado (como as religiões, a escola, etc.). Entretanto, o pensamento de Althusser baseia-se em como as instituições formam os sujeitos ideologicamente. Sujeito este que se torna assujeitado por não enxergar a verdadeira realidade, fazendo do mascaramento sua verdade eterna. Essa teoria de Althusser (1998) é bastante criticada atualmente, ao lado de outras teorias, como Adorno (1984), que localiza o sujeito como não pensante, ou sem ideias livres fora da lógica consumista/capitalista. Althusser não foge das posições reducionistas que $o$ marxismo tanto proporcionou nas últimas décadas, como pensar a dominação e a ideologia apenas como instrumentos da classe dominantes, deixando de lado o cotidiano e o processo conversacional. Uma dessas questões encontramos em Foucault (2008): o discurso em si como forma de poder.

Žižek (1996a, p. 29), por outro lado, aborda a ideologia como uma fantasia. Uma obliteração e ocultação como forma de uma aparição espectral "que preenche o buraco do real". O autor analisa a ideologia como uma fantasia, a partir do retorno ao Freudismo, elaborado por Lacan. Para Žižek 
EID\&A - Revista Eletrônica de Estudos Integrados em Discurso e Argumentação, Ilhéus, n. 12, jul/dez.2016.

(1996a, p. 28), “(o que vivenciamos como) realidade não é a própria coisa, é o sempre já simbolizado, constituído, estruturado por mecanismos simbólicos". A ideologia não estaria dissimulando um real verdadeiro (como resto daquilo que não foi simbolizado), mas apareceria a partir de um antagonismo real:

O importante é que a própria constituição da realidade social implica o "recalcamento primário" de um antagonismo, de modo que o esteio fundamental da crítica da ideologia - o ponto de referência extra-ideológico que nos autoriza a denunciar o conteúdo de nossa experiência imediata como "ideológico" - não é a "realidade", mas o real "recalcado" do antagonismo (ŽIŽEK, 1996a, p. 33)

O apontamento sobre o "recalcamento primário" de Žižek quer dizer que o aparecimento de um espectro ideológico só é realizável a partir do real simbolizado, não tendo como fundamento teórico uma realidade fechada. Segundo ele, "[...] para que emerja (o que vivenciamos como) a "realidade" algo tem que ser foracluído dela - em outras palavras, a "realidade", tal como a verdade, nunca é, por definição, “toda" (Ibid., p. 26). O real como antagonismo emerge como uma transposição ao conceito marxista de lutas de classes. Para Žižek (1996), a luta de classes representaria um "real” não fechado, porém determinante para o conceito de ideologia. Ao pensar sobre o conceito de lutas de classes, Žižek (1996a) repassa o estudo de Balibar sobre como o materialismo histórico concebe a luta de classes como uma realidade totalizante, sem perceber que essa realidade não pode ser fechada em si mesma.

Portanto, ao imaginar a realidade em torno de um antagonismo real, Žižek (1996a), propõe uma análise ideológica a partir de que o conceito de ideologia não mascara o real estado das coisas (concretas e não simbolizadas), mas é resultado de uma obliteração de nossa própria realidade ou de uma falsa consciência. A sociedade atual viveria em torno de um cinismo ideológico do "Eles sabem o que fazem e continuam fazendo".

Essa, provavelmente, é a dimensão fundamental da "ideologia": a ideologia não é simplesmente uma "falsa consciência", uma representação ilusória da realidade; antes, é essa mesma realidade que já deve ser concebida como "ideológica": "ideo1ógica" é uma realidade social cuja própria existência implica o não-conhecimento de sua essência por parte de seus participantes, ou seja, a efetividade social cuja própria reprodução implica que os indivíduos "não sabem o que fazem". "Ideo1ógica" não é a 'falsa consciência" de um ser (social), mas esse próprio ser, na medida em que ele é sustentado pela 'falsa consciência" (ZIZEK, 1996b, p. 305-306 - destaques do autor) 
Guilbert (2007), em um estudo mais recente e entorno da Análise do Discurso, reflete sobre o desgaste do conceito de ideologia ao longo do tempo. Segundo Figueiredo (2013), citando Guilbert, três movimentos contribuíram para este desgaste científico da ideologia: quando Napoleão Bonaparte rejeitou a doutrina irrealista e sectária; quando Marx elaborou o conceito de ideologia como ilusória e diretamente ligada a uma classe dominante; e, por último, quando a sociologia determinou que a ideologia serviria, implicitamente, como um código para um projeto comum entre os indivíduos na sociedade.

Após contextualizar os estudos sobre ideologia, Guilbert divide o conceito de ideologia em dois níveis: o primeiro voltado para a natureza da ideologia (como os estudos de Althusser (1998) sobre os Aparelhos Ideológicos do Estado, e a Doxa); e o segundo, intermediário, com os tipos de ideologia diretamente ligados à crença e ao conhecimento partilhados.

Contrastando conceitos de ideologia desde Althusser (1998), Bourdieu (1982) e Reboul (1980), e ressaltando a importância do último, Guilbert (2007) propõe que a materialização da ideologia se dá pela legitimação de um poder e de um sagrado. Essa sacralização (legitimação do poder e do sagrado) é feita em um terreno onde são partilhadas posições de conduta ao dizer, que se assemelham aos conceitos de Charaudeau (2008) e Foucault (2008). O que pode e não pode ser dito determina como é construída a materialização da ideologia no dizer.

Em outras palavras, existem duas formas de caracterização da ideologia imersas entre sua natureza e sua materialidade. Segundo Guilbert (2007), o sagrado mostrado (sacré montré) ocorre quando a ideologia se expõe como efeitos de naturalização, sendo seu elemento de legitimação, por exemplo, a existência de Deus, perpassando para os conceitos gerais de democracia, nação e de vontade do povo. Por outro lado, servindo como fundição para a operacionalização da ideologia, existe o sagrado constitutivo (sacré constitutif) que tem a função de dissimular, ou seja, de disfarçar ideologicamente um poder, um sagrado, uma vontade.

Essa função de dissimular e naturalizar ocorre pelo discurso. A ideologia e o discurso, em Guilbert (2007) se interligam, por a ideologia do sagrado ter a necessidade do discurso para se legitimar. 
EID\&A - Revista Eletrônica de Estudos Integrados em Discurso e Argumentação, Ilhéus, n. 12, jul/dez.2016.

\section{Interação nas redes sociais}

Antes de entrar em novos conceitos de interação imersos em mídias sociais digitais, voltemos a Thompson (2008) e suas contribuições sobre a interação. Segundo o autor, existem três tipos de interação: a) face-face, quando a comunicação entre os falantes se dá por espaço e tempo iguais; b) mediada, quando a comunicação entre os falantes se faz por meio de um aparato tecnológico (como telefone etc.); podendo ter espaços diferentes entre os locutores; c) quase-mediada quando não há retorno imediato entre os falantes; citando como exemplo os meio de comunicação em larga escala em relação aos receptores.

A internet, ou, mais precisamente, as redes sociais, poderiam integrar duas formas de interação: ela pode ser mediada por estar auxiliada por um aparelho tecnológico, como celular, computador, notebook, entre outros; e ser quase mediada, por não tratar de interação imediata, ou seja, o interlocutor pode se expressar num espaço-temporal diverso.

Recuero (2009) realiza um amplo estudo sobre os elementos das redes sociais. Em seu livro As redes sociais, ela sintetiza estes elementos entre atores e conexões. Os atores são as representações sociais que os usuários da rede "transportam" para dentro do universo online, formando os nós ou nodos da rede. Não se trata de indivíduos e sim de construções de representação dos atores. As conexões são as relações sociais destes atores dentro da rede. São os laços sociais, relações sociais, e as interações. O laço social, segundo a autora, é a "efetiva conexão entre os atores que estão envolvidos nas interações. Ele é resultado, deste modo, da sedimentação das relações estabelecidas entre agentes" (RECUERO, 2009, p. 38).

A interação nestas mídias digitais, segundo Donath (1999, apud RECUERO, 2012, p. 27), "sustenta que a percepção do Outro é essencial para a interação humana". Recuero (2009) explica que existem duas formas de interação: a reativa e a mútua. A mútua seria expressa por sujeitos diversos, com bate-papos e debates em comentários ou postagens ${ }^{1}$. A reativa se realiza por meio de ligações entre sites, os chamados links. Para Recuero (2019), a interação reativa ocorre quando um locutor publica um endereço de site. Os outros interlocutores só interagem com o link: se clicam ou não.

\footnotetext{
${ }^{1}$ A interação pode ou não ser imediata. Por exemplo, um comentário postado no início de maio de 2014, pode receber novas respostas no início de junho de 2015.
} 
EID\&A - Revista Eletrônica de Estudos Integrados em Discurso e Argumentação, Ilhéus, n. 12, jul/dez.2016.

As relações sociais são construídas por meio da interação e das conexões de laços sociais. Recuero (2019) trabalha no enfoque de Capital Social, nos conceitos de Bourdieu (1983), Coleman (1988) e Putnan (2000). O conceito de capital social refere-se às relações de um grupo entre atividades individuais e coletivas, por meio de experiências de moralidade, das redes sociais (grupos) e das normas cívicas. A partir desse jogo de relações, o indivíduo expressa o valor social resultado de suas experiências.

Portanto, as trocas enunciativas dentro das redes sociais digitais ocorrem de duas maneiras: pelos atores sociais e por conexões. Como vimos, os atores imersos na rede são representações (construções) que interagem por meios das conexões (interação, laços sociais, e relações sociais) através do valor social agregado ${ }^{2}$.

\section{Análise dos elementos discursivos}

O material de análise deste trabalho foi colhido em três páginas de jornais tradicionais imersos na rede social Facebook. São eles: O Estado de São Paulo, O Globo, e Folha de São Paulo. Sobre a postagem com o tema: Cuba é o primeiro país a eliminar a transmissão de Aids de mãe para filho, foi colhido o primeiro comentário de 3 postagens dos jornais supracitadas, contendo 186 respostas ou réplicas.

É importante frisar que o momento atual em que o Brasil se encontra é delicado. Depois das Eleições de 2014, que marcaram por ser uma das mais acirradas dos últimos anos, o país dividiu-se entre as pessoas pró e contra governo, o que culminou com manifestações em todo o país reivindicando o impeachment da Presidente Dilma.

O interesse deste trabalho é identificar e analisar se há resquícios ideológicos da Guerra Fria em discursos de ódio no Facebook. Muito se fala, atualmente, na extinção das correntes de direita e esquerda, por não se poder delimitar uma polarização eficiente. Entretanto, como afirma Bakhtin (2006), todo emprego de signo é ideológico, as palavras são por si só ideológicas e o que temos para analisar são estes reflexos de ideologias mascaradas ou mostradas em comentários do Facebook, ou seja, a materialidade linguístico-

\footnotetext{
${ }^{2}$ Bourdieu (1983) conceitua o capital social baseado em seus conceitos de Habitus e Conflito. Segundo Bourdieu (1986), o agregado de recursos potenciais relacionados a uma rede de relações institucionalizadas de mútua familiaridade e reconhecimento é uma definição do capital social. É a mútua troca de membros de um grupo que dão o direito de se expressar, de vender, etc., dentro de seu universo simbólico.
} 
EID\&A - Revista Eletrônica de Estudos Integrados em Discurso e Argumentação, Ilhéus, n. 12, jul/dez.2016.

discursiva do fenômeno. Por mais que não seja possível delimitar direita e esquerda, a análise discursiva pode apontar estes reflexos.

A imagem abaixo demonstra um discurso de ódio semelhante a quem se dirige a uma pessoa que não compartilha da mesma opinião. No caso, a notícia sobre o fim da transmissão de Aids de mãe para filho é recebida como falsa, como se o governo Cubano tivesse o poder de se alavancar a partir da Organização Mundial da Saúde (OMS).

\section{Figura 1: Réplicas na página do jornal O Globo}

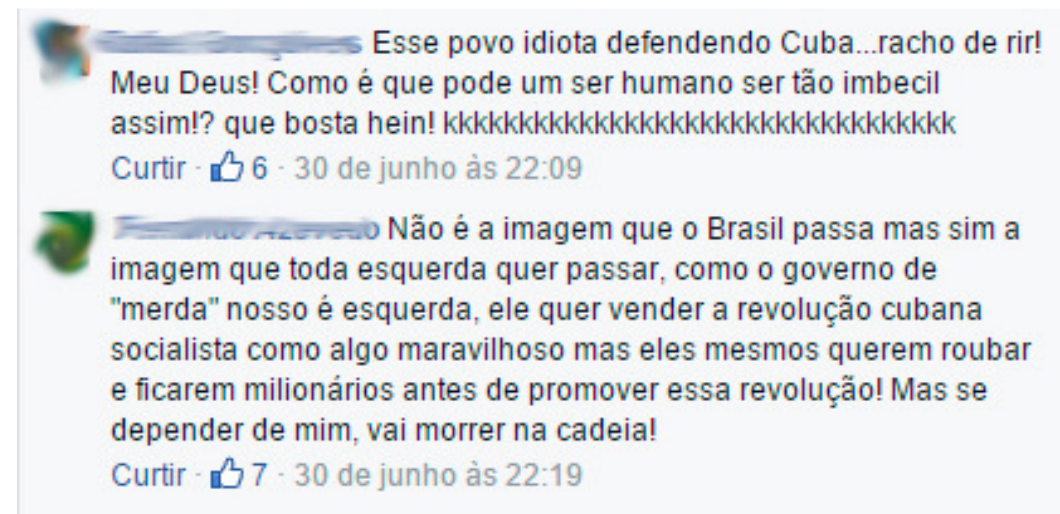

Vemos marcações que delimitam a intenção dos locutores de agressão verbal. Primeiro "imbecis", no segundo "morrer na cadeia". O discurso de ódio, qualquer que seja o tema ou contexto, sempre ocorre pela agressão verbal, isto é, o dissenso se sobrepõe sobre o senso.

No segundo enunciado, o usuário afirma que toda a esquerda quer passar a imagem de que a Revolução Cubana foi algo maravilhoso, e que na verdade, a esquerda quer é ficar com o dinheiro do povo. Temos aqui, segundo Guilbert (2007), um tipo de ideologia de sacralização mostrada. Retomemos que, para o autor, o sagrado mostrado ocorre como a existência de Deus, a democracia, a nação, ou seja, como concepções não palpáveis da realidade. Portanto, há um sagrado mostrado nos dois enunciados acima que revela a concepção anterior de que socialismo não existe, e se existe, é uma das piores formas de poder no mundo.

Mas como podemos dizer isso? O sagrado mostrado de Guilbert (2007) se revela como um processo de naturalização de um determinado discurso. São agenciamentos anteriores que perpassam de geração a geração por meio do discurso. Analogias ligadas ao comunismo como ditadura, ou como terroristas, estão ligadas a essa memória que permeia gerações. Guilbert 
EID\&A - Revista Eletrônica de Estudos Integrados em Discurso e Argumentação, llhéus, n. 12, jul/dez.2016.

(2007) cita exemplos como a existência de Deus. Isto é, o mundo é repleto de religiões, mas a maioria deles acredita em Deus ou em um ser superior. Esse ser superior é um aspecto de uma ideologia não verificável.

Além disso, há uma característica ideológica: a deslegitimação do outro. Os dois enunciados tratam o assunto primeiro com posições negativas para confirmar suas convicções, alimentadas pelo discurso de ódio. Na Figura 2, há um diálogo entre os usuários sobre a vida dos cubanos. Uma locutora enuncia que conhece pessoas que deixaram Cuba e afirma "com absoluta certeza" que lá "é uma tristeza":

\section{Figura 2: Comentário e réplicas na página do jornal O Globo}

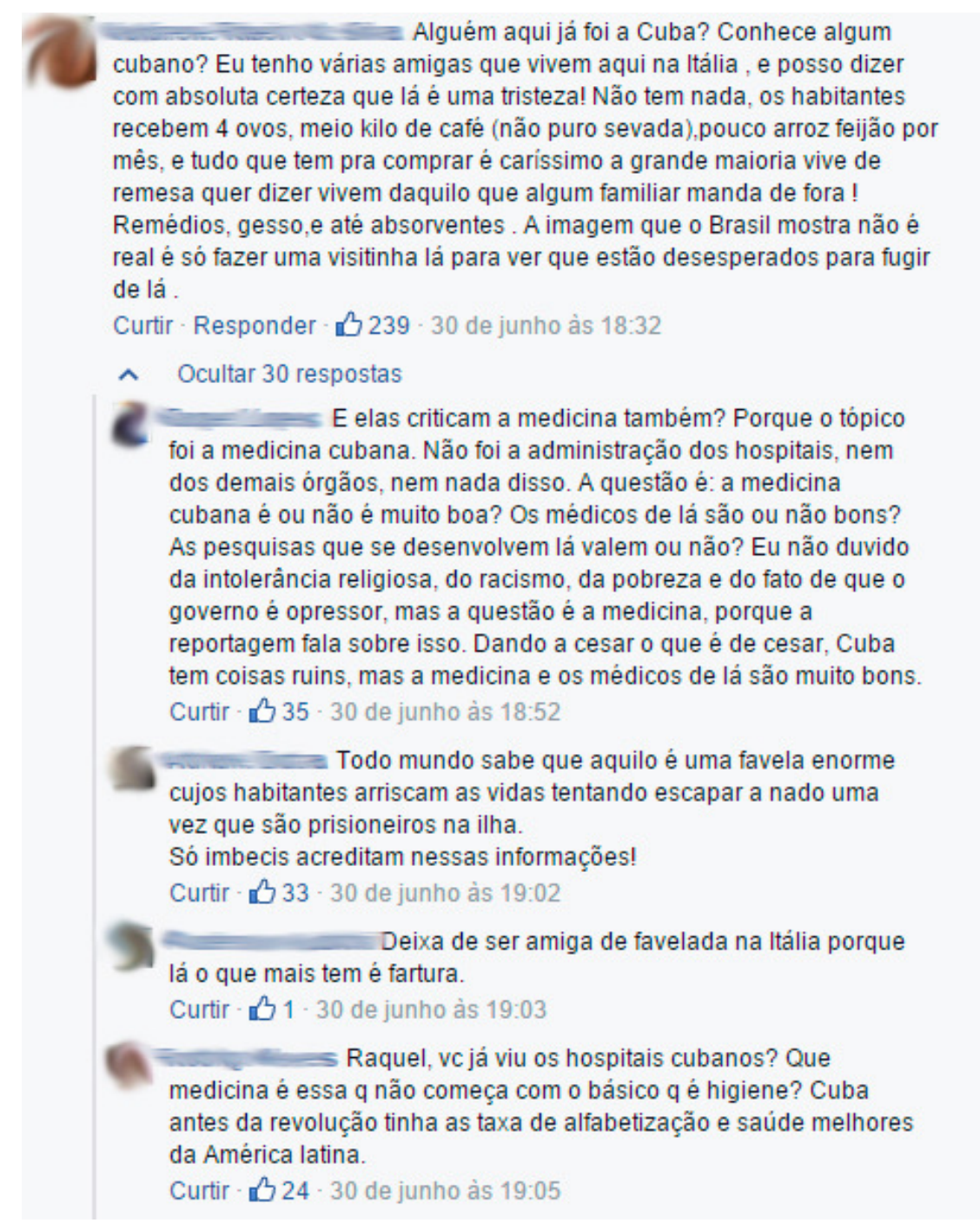

Como podemos identificar, há nos enunciados acima uma relação de ódio a quem noticia e a quem "acredita" em notícias vindas de países fora do 
EID\&A - Revista Eletrônica de Estudos Integrados em Discurso e Argumentação, Ilhéus, n. 12, jul/dez.2016.

bloco União Europeia e Estados Unidos. São chamadas de "imbecis" e até expostas de maneira a ameaças de mortes por alguns usuários.

A prática desses atos de agressão verbal dos dois lados (temos o exemplo da segunda resposta que nomeia o usuário-primeiro de "favelada") são reflexos desta hegemonia ocidental. Do ponto de vista histórico, vemos a relação EUA x URSS veladamente nos comentários. O combate excessivo ao chamado socialismo cubano se assemelha ao que foi relatado em Motta (2001) de anticomunismo como uma indústria, forjado para aprofundar, à primeira vista, a iminência de uma insurreição comunista, mas também como a garantia de vantagens, como adição de setores da sociedade a esse combate. Esse diálogo anticomunista, reflete Motta (2001), também é reforçado a partir do rótulo de comunista para deslegitimar adversários. Vemos abaixo, que a réplica da Figura 3 é de uma pessoa que não duvida da proeminência da Organização Mundial da Saúde (OMS) e se preocupa com os avanços da medicina em qualquer país, sem distinção ou exclusão políticopartidária. Por outro lado, o comentário abaixo (Figura 4) já nomeia as pessoas que defendem a medicina cubana como "parasitas da esquerda" e até declama "morte à esquerda", definindo-a como a escória da humanidade.

\section{Figura 3: Réplica na página do jornal O Globo}

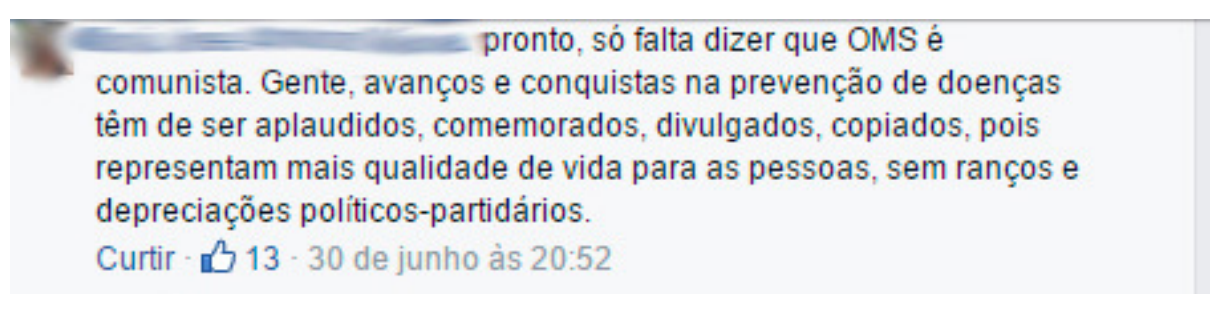

Figura 4: Réplica na página do jornal O Globo

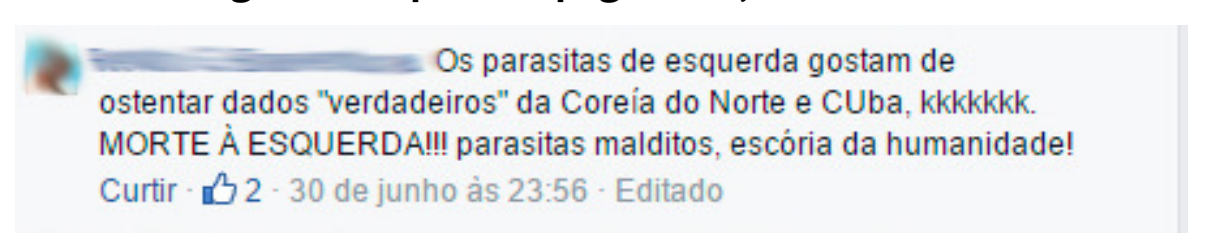

Temos duas ideologias combatentes e contrastantes. A primeira em torno do bem-estar social, um sagrado mostrado (GUILBERT, 2007) de que a saúde sempre deve prevalecer em relação ao poder, e do outro, uma ideologia fantasmática e dogmática, retomando Zizek (1996b). Fantasmática porque já demonstra uma verdade admitida de que a esquerda "destrói" o planeta, destruirá a vida dos povos se chegar ao poder. É o processo de antagonismo real 
EID\&A - Revista Eletrônica de Estudos Integrados em Discurso e Argumentação, llhéus, n. 12, jul/dez.2016.

de Zizek (2006), que afirma que não é possível chegar à realidade propriamente dita, e sim à nossa própria realidade ou à nossa falsa consciência. Isso reflete também a Bakhtin (2006) sobre a polifonia. Este discurso de ódio pode ser reflexo da Guerra Fria, em um primeiro plano, e da Ditadura Militar Brasileira, em segundo plano. Os dois fatos históricos foram marcados por um mascaramento da verdade sobre o que seria comunismo (como até comentários de que comunistas seriam canibais) e como uma indústria anticomunista (MOTTA, 2001), com instituições responsáveis para alimentar este ódio, como a Ação Integralista (ABI), além do IPES (Instituto de Pesquisas e Estudos Sociais) e a IBAD (Instituto Brasileiro de Ação Democrática), refletidos em artigo de Mendes (2004), reforçaram a obliteração do real. Isso reflete também os comentários dos usuários nas outras páginas. São já-ditos que perpassam décadas e se materializam ideologicamente nos enunciados abaixo:

\section{Figura 5: Réplicas na página do jornal Estado de São Paulo}

\footnotetext{
1. Caus Porque os PcdoB se mandam pra Venezuela Coréia do Norte ou.mesmo no Irã é legal ser comunista na democracia Curtir - 3 - 30 de junho às 21:54

\section{Dá tempo!}

Curtir - 4 - 30 de junho às 21:56

1 Outro detalhe é que essa questão da erradicação não é exatamente algo complicado, mas sim atenção básica a saúde. O governo colocou pra valer o pré natal lá. A mamãe tomou as vacinas, fez as medicações corretas, fez as consultas de rotina, fez a cesárea, não amamentou e o bebê foi medicado. Qual o mistério?

Curtir - 32 - 30 de junho às 21:58

4 Vim Fábio, você é burro sim, e o Brasil é um país populoso, tem burro pra caralho nessa porra aqui. Não se vanglorie pelas dedadinhas facebookianas que você tomou.

Curtir - 35 - 30 de junho às 22:01

A $\mathrm{L}$ Citar as qualidades de Cuba para algumas pessoas daqui é como se você estivesse fazendo uma adoração ao capeta.

Engraçado que essas pessoas que tanto clamam por educação insistem em desvalorizar dessa maneira a nação com a menor taxa de analfabetismo da América Latina.

Curtir - 10 - 30 de junho às 22:02

I Vão morar na Cubinha do Fidel esquerdopatas. Por favor levem o Lula assaltante com voçês OK.. Fora PT lixo!! Curtir - 35 - 30 de junho às 22:03

Mas puta merda ... porque esses

idolatradores de Cuba não se enfiam naquela favela? VÁ PRA CUBA QUE O PARIU.

Curtir - 13 - 30 de junho às 22:03
} 
Detalhe para o quinto comentário da Figura 5: "Citar as qualidades de Cuba para algumas pessoas daqui é como se você estivesse fazendo adoração ao capeta". Essa frase demonstra também uma sacralização. Guilbert (2007), retomando-o, propõe que a ideologia pode se materializar na forma de um sagrado mostrado como elemento de legitimação, e de um sagrado constitutivo que tem a função de dissimulação da realidade.

O processo de legitimação (sagrado mostrado) pode aparecer nas recorrências de notícias e diálogos do quotidiano (em um contexto social específico) que utilizam esse caráter de "comunismo" como ditadura (a exemplo de Stalin) para constituir a dissimulação dos benefícios da medicina cubana. Esse discurso de ódio é reflexo, poderíamos propor aqui, desse diálogo, ou dialogismo (se preferirmos o termo Bakhtiniano), entre União Soviética (URSS) e Estados Unidos (EUA), representando o feixe entre o capitalismo e socialismo ocorrido no pós-guerra. As réplicas acima também se ligam ao principal slogan da Ditadura Civil-Militar: Brasil - Ame-o ou Deixe-o. Réplicas como "VÁ PARA CUBA QUE O PARIU", nos mostram a retomada de discurso conservadores e reacionários da década de 1960.

Até hoje existem estes diálogos sobre quão mal pode ser o comunismo para a sociedade. Reflexo que também atinge o governo do PT, no sexto comentário da Figura 5. Os comentários da Figura 6, expostos na página do jornal Estado de São Paulo, também indicam essa retomada de outros dizeres (BAKHTIN, 2006). 
EID\&A - Revista Eletrônica de Estudos Integrados em Discurso e Argumentação, llhéus, n. 12, jul/dez.2016.

\section{Figura 6: Comentário e réplicas na página do jornal Estado de São Paulo}

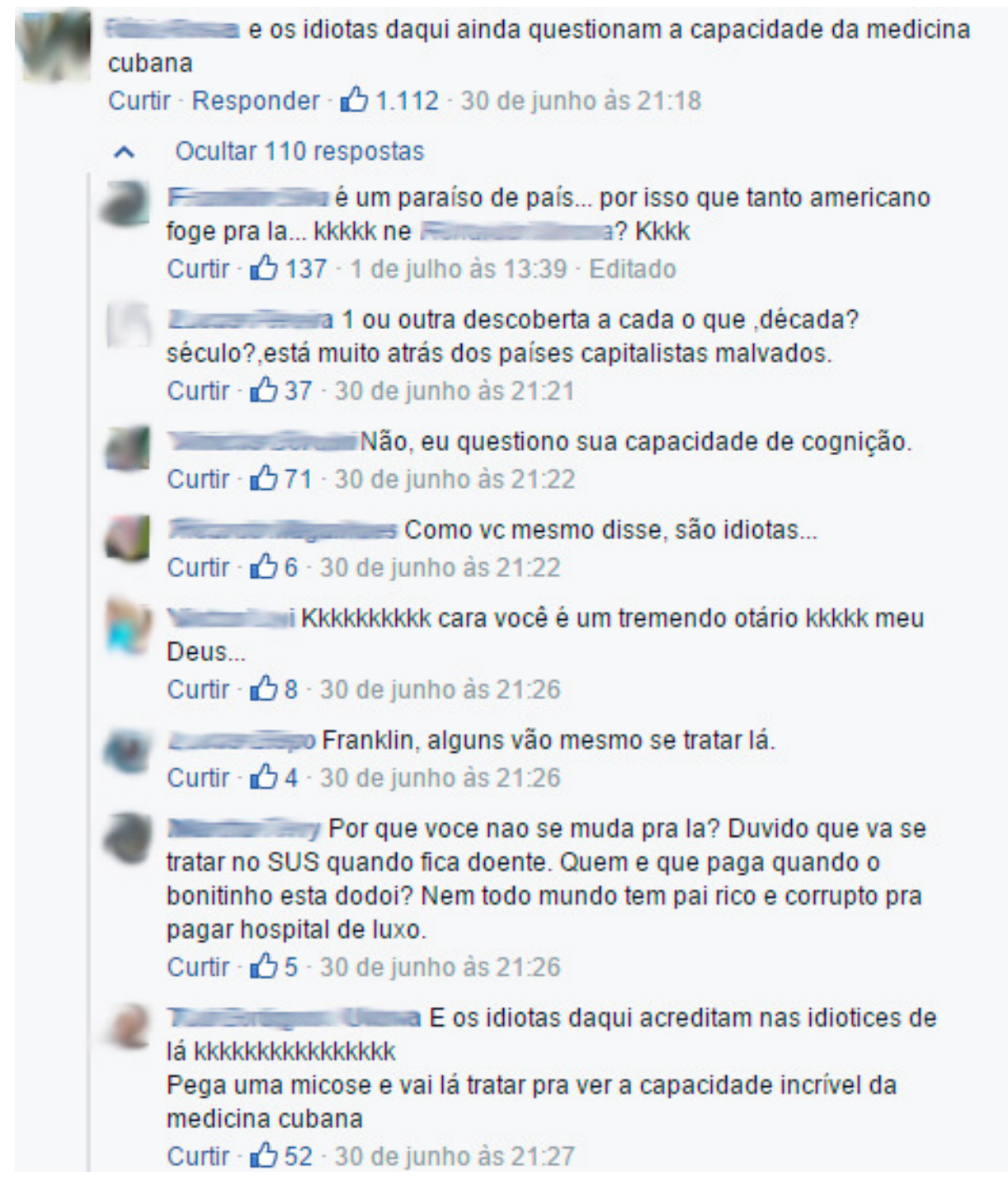

Os comentários, na Figura 6, retomam o que Zizek (1996b) vai chamar de sintoma criado por Marx em seus escritos sobre o Capital. Para Zizek (1996b), quando Marx revela que a relação entre servidão e dominação, no précapitalismo, estaria evidente nas relações sociais com as coisas, isto é, no fetiche da mercadoria, a condição de nossa sociedade atual estaria na ideologia do cinismo, como se os sujeitos soubessem a verdadeira situação das coisas, mas mesmo assim continuam fazendo da mesma forma, como, na Figura 7, abaixo, em que se afirma que a luta de valores (ou ideologias) supera o "humanismo". 
EID\&A - Revista Eletrônica de Estudos Integrados em Discurso e Argumentação, Ilhéus, n. 12, jul/dez.2016.

\section{Figura 7: Comentário na página do jornal Folha de São Paulo}

Em vez de comemorar a galera vem atacar o país.

Quando o ódio ideológico supera o humanismo e o amor.

Curtir-Responder - 1.231 - 30 de junho às 18:09

Logo, outros usuários refutam o caráter humanista quando apontam para os defensores de Cuba saírem do Brasil. Na Figura 8, outros dizeres também são plantados, como o "pão com mortadela". Em manifestação no dia 13 de março de 2015, na avenida Paulista, diversos setores como a CUT (Central Única dos Trabalhadores) e o MST (Movimentos dos Trabalhadores Rurais Sem Terra), protestaram a favor do governo Dilma Rousseff. Na ocasião, a oposição acusou os sindicatos e movimentos de distribuírem pães com mortadela aos manifestantes.

Figura 8: Comentário na página do jornal Folha de São Paulo

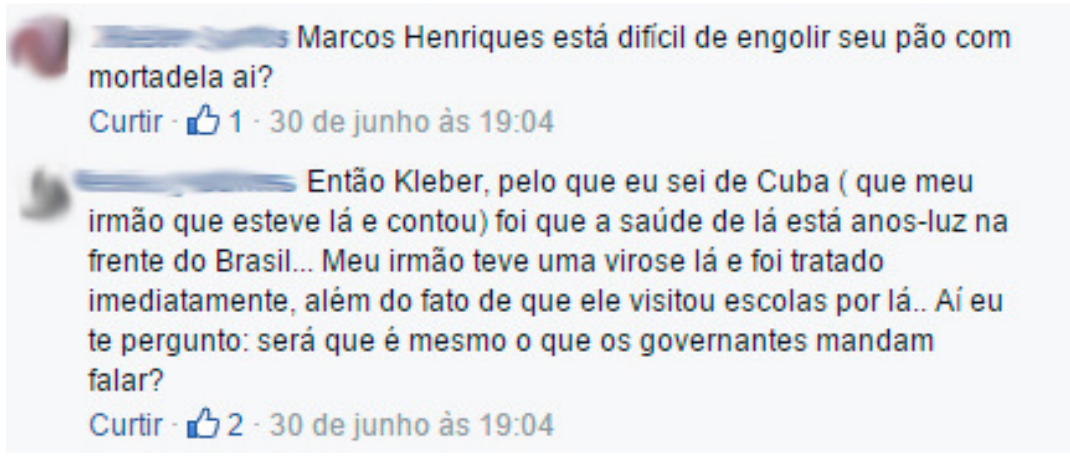

Isso demonstra o quanto Bakhtin (2006) tem razão em encarar o fenômeno da interação verbal como a verdadeira substância da língua. Esse dialogismo que fornece essa arena como vemos na Figura 9, abaixo:

Figura 9: Comentário na página do jornal Folha de São Paulo

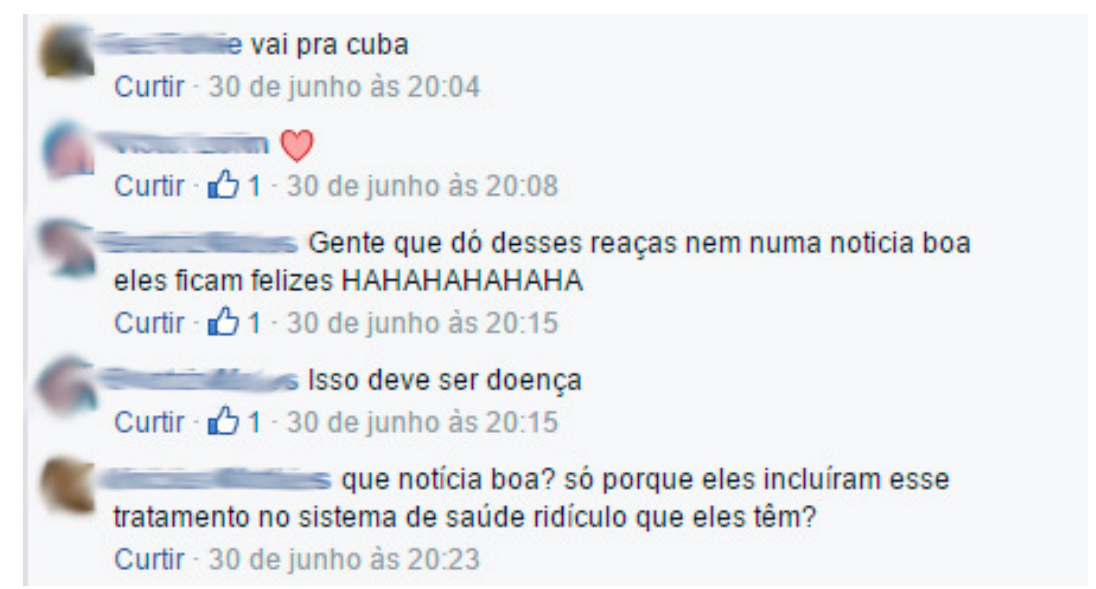


EID\&A - Revista Eletrônica de Estudos Integrados em Discurso e Argumentação, Ilhéus, n. 12, jul/dez.2016.

Portanto, o discurso de ódio nas redes sociais não pode ser tomado como novo. Bakhtin (2006) já afirma esse caráter polifônico e dialógico da linguagem: o sujeito não é dono do seu dizer. Os discursos aqui apresentados demonstram o quanto estes enunciados são reflexos de conotações ligadas à direita e esquerda, no pós-guerra, a chamada Guerra Fria.

\section{Considerações finais}

Retomando Guilbert (2007), o processo ideológico pode ser caracterizado por uma sacralização que legitima e tem a função de dissimular a realidade. De outro lado, Zizek (1996a; 1996b) afirma que o antagonismo real, o caráter de luta e arena na sociedade, são frutos da ideologia, e que não é possível sair dela, pois o verdadeiro real não é simbolizado. Seria um resto que não fora categorizado pelos humanos. E por último, Bakhtin (2006), afirma que todo emprego de signo é ideológico.

Portanto, os comentários que analisamos neste trabalho refletem estes caráteres de deslegitimação na arena discursiva de uma ideologia de direita ou de esquerda a partir de outras vozes, ou seja, a partir da polifonia imersa dentro dos enunciados. É preciso compreender que o discurso de ódio é tomado aqui como um conjunto de enunciados regulares e parcialmente estáveis que busca ferir o outro, seja por sua etnia, orientação sexual, situação econômica, entre outros predicados com viés de humilhação e/ou hostilização. Logo, o discurso de ódio não é reflexo apenas das redes sociais, mas reflexos de processos sócio-históricos que ainda se materializam no dizer.

O que vimos em nossa análise é uma obliteração de um sagrado de bemestar social, como a saúde, ser invertido e polarizado como forma de legitimação dos dizeres dos usuários da rede. Não obstante que a notícia seja um avanço na saúde internacional, o que compôs o conteúdo das réplicas foram as filiações de direita e esquerda. Guilbert (2007) propõe que a ideologia pode se materializar na forma de um sagrado mostrado como elemento de legitimação, e de um sagrado constitutivo que tem a função de dissimulação e naturalização da realidade. Identificamos, desse modo, na Figura 3, a ideologia mostrada: "os parasitas de esquerda"; "morte à esquerda", sendo composta pelo sagrado mostrado "verdadeiros" Cuba e Coreia do Norte, e pelo sagrado constitutivo: medo, raiva e violência gerados a partir da memória. 
EID\&A - Revista Eletrônica de Estudos Integrados em Discurso e Argumentação, Ilhéus, n. 12, jul/dez.2016.

Apesar de não estar explícita a contribuição para a reflexão sobre argumentação, pois não enfatizamos uma articulação com questões sobre, este artigo favorece à reflexão a ponto de compreender como o discurso de ódio também possui caráter argumentativo e é capaz de direcionar sentidos e práticas ideológicas de uma determinada sociedade.

Nosso trabalho não é uma conclusão de que os comentários de usuários do Facebook são extremamente forjados com base nesta polarização, mas o que podemos compreender é a capacidade desta nova arena funcionar como uma ferramenta de legitimação em nossa democracia. Poderíamos em outros trabalhos, analisar estas agressões verbais a partir de uma retórica do dissenso (AMOSSY, 2014), para compreender como o discurso polêmico ocupa um plano central em nossa sociedade.

\section{Referências}

AMOSSY, Ruth. Apologie de la polémique. Paris: PUF, 2014.

ALTHUSSER, Louis. (1970). Aparelhos Ideológicos de Estado. Trad. Walter José Evangelista e Maria Laura Viveiros de Castro. 7.ed. Rio de Janeiro: Edições Graal, 1998.

BAKHTIN, Mikhail. Estética da criação verbal. São Paulo: Martins Fontes, 1997.

BAKHTIN, Mikhail. Marxismo e filosofia da linguagem. 12.ed. São Paulo: Hucitec, 2006.

BOURDIEU, Pierre. The forms of capital. In: RICHARDSON, J. (Ed.). Handbook of Theory and Research for the Sociology of Education. New York: Greenwood, 1986. p. 241-258.

CHARAUDEAU, Patrick. Linguagem e Discurso: os modos de organização do discurso. São Paulo: Contexto, 2008.

FOUCAULT, Michel. A ordem do discurso. São Paulo: Loyola, 2014.

FIGUEIREDO, Ivan. Imaginários sociodiscursivos sobre a surdez: análise contrastiva de discursos do jornal visual a partir da produção e recepção. Tese (Doutorado). UFMG, Faculdade de Letras, 2013.

GUILBERT, Thierry. Le Discours Idéologique ou la Force de l'évidence. Paris: L'Harman-ttan, 2007. 
EID\&A - Revista Eletrônica de Estudos Integrados em Discurso e Argumentação, Ilhéus, n. 12, jul/dez.2016.

MENDES, Ricardo Antonio Souza. As direitas e o anticomunismo no Brasil. Locus: Revista de História, v. 10, n. 01, 2004.

MOTTA, Rodrigo Patto Sá. A “indústria” do anticomunismo. Revista Anos 90, v. 9, n. 15, 2001.

RECUERO, Raquel. As redes sociais. Porto Alegre: Sulina, 2009. (Coleção Cibercultura)

THOMPSON, John B. A mídia e a modernidade: uma teoria social da mídia. Petrópolis: Vozes, 1998.

ŽIŽEK, Slavoj. O espectro da ideologia. In: ŽlŽEK, S (Org.). Um mapa da ideologia. Trad. Vera Ribeiro. Rio de Janeiro: Contraponto, 1996a. p. 7-38.

ŽIŽEK, Slavoj. Como Marx inventou o sintoma? In: ŽlŽEK, S (Org.). Um mapa da ideologia. Trad. Vera Ribeiro. Rio de Janeiro: Contraponto, 1996b. p. 297-331.

Forma de citação sugerida:

MACHIAVELI, Gabriel Reis Moraes. Saúde em Cuba: discurso de ódio e retomadas de discursos conservadores. EID\&A - Revista Eletrônica de Estudos Integrados em Discurso e Argumentação, Ilhéus, n. 12, p. 84-100, jul/dez.2016.

Recebido em: 30/10/2016

Aprovado em: 22/12/2016 